\title{
Regulating $\mathrm{Na}$ Occupation to Introduce Non-Fermi-liquid States of $\mathrm{Na}_{x} \mathrm{CoO}_{2}$ for Enhanced Water Oxidation Activity
}

Xiaoning Li ${ }^{1}$, Wei Sun², Chongyan Hao ${ }^{1,3}$, Ying Bai ${ }^{2}$, Zhengping $\mathrm{Fu}^{3}$, Yalin Lu ${ }^{3}$, Xiaolin Wang ${ }^{1}$, and Zhenxiang Cheng ${ }^{1 *}$

${ }^{1}$ Institute for Superconducting and Electronic Materials (ISEM), University of Wollongong, Wollongong 2500, Australia

${ }^{2}$ International Joint Research Laboratory of New Energy Materials and Devices of Henan Province, School of Physics and Electronics, Henan University, Kaifeng 475004, People's Republic of China

${ }^{3}$ Department of Materials Science and Engineering, University of Science and Technology of China, Hefei 230026, P. R. China 


\section{MATERIALS AND METHODS}

Sample preparation. All the chemicals used in the present work, including the $\mathrm{Co}\left(\mathrm{NO}_{3}\right)_{2} \cdot 6 \mathrm{H}_{2} \mathrm{O}(\geq 98 \%), \mathrm{Na}_{2} \mathrm{CO}_{3}(\geq 99.5 \%), \mathrm{NaOH}(\geq 97 \%)$, and Nafion 117 solution, were purchased from Sigma-Aldrich Ltd. The $\mathrm{Na}_{x} \mathrm{CoO}_{2}(0.4 \leq x \leq 0.8)$ samples were prepared by the solid-state reaction of $\mathrm{Na}_{2} \mathrm{CO}_{3}$ with (111)-facet dominated $\mathrm{Co}_{3} \mathrm{O}_{4}$, which was synthesized by the molten alkaline flux method.

Preparation of $\mathrm{Co}_{3} \mathrm{O}_{4}$. First, $1.455 \mathrm{~g} \mathrm{Co}\left(\mathrm{NO}_{3}\right)_{2} \cdot 6 \mathrm{H}_{2} \mathrm{O}$ and $14.55 \mathrm{~g} \mathrm{NaOH}$ were put into a platinum crucible and covered with a platinum lid. Then, they were heat-treated in a muffle furnace at $400{ }^{\circ} \mathrm{C}$ for 12 hours. After cooling down to room temperature, the calcined black powder mixed with recrystallized $\mathrm{NaOH}$ bulk was immersed in water with ultrasound to dissolve and wash the $\mathrm{NaOH}$ away by centrifugation. The collected black powder was dried at $110{ }^{\circ} \mathrm{C}$ for 12 hours and ground into a $\mathrm{Co}_{3} \mathrm{O}_{4}$ powder.

Preparation of $\mathrm{Na}_{\mathrm{x}} \mathrm{CoO}_{2}(0.4 \leq \mathrm{x} \leq 0.8)$. According to the stoichiometric ratio of $\mathrm{Na}_{x} \mathrm{CoO}_{2}$, certain amounts of $\mathrm{Na}_{2} \mathrm{CO}_{3}$ and $\mathrm{Co}_{3} \mathrm{O}_{4}$ powders were mixed together with thorough grinding. Thereafter, they were heated at $800{ }^{\circ} \mathrm{C}$ for 12 hours in a muffle furnace under ambient atmosphere and ground into a fine powder when cooled down naturally. The NCO04, NCO05, NCO06, NCO07, and NCO08 sample labels denote the $\mathrm{Na}_{\mathrm{x}} \mathrm{CoO}_{2}$ samples when $x$ equals $0.4,0.5,0.6,0.7$, and 0.8 , respectively.

Characterizations. X-ray powder diffraction (XRD) patterns of all samples were recorded on a PANalytical Empyrean X-ray diffractometer with $\mathrm{Cu}-\mathrm{K} \alpha$ radiation. Scanning electron microscope (SEM) and element mapping images were obtained on a JEOL JSM-7500FA. The high-angle annular dark field (HAADF) observations were 
conducted on a scanning transmission electron microscope (STEM, JEOL JEMARM200F). The X-ray photoelectron spectra (XPS) were conducted on a NEXSA Xray photoelectron spectrometer (Thermo Scientific) without ion etching. The Co L-edge and O K-edge soft X-ray absorption spectra (sXAS) were collected from the Soft X-ray Spectroscopy beamline at the Australian Synchrotron (AS, Australia), part of the Australian Nuclear Science and Technology Organization (ANSTO).

OER measurements. To prepare the working electrodes, $0.75 \mathrm{~mL}$ deionized water, 0.25 $\mathrm{mL}$ isopropanol, $2 \mathrm{mg}$ carbon powder, $10 \mathrm{mg}$ of electrocatalyst, and $0.1 \mathrm{~mL}$ of Nafion 117 solution were mixed under ultrasound for 1 hour to form a homogenously mixed ink. Then, $3 \mu \mathrm{L}$ of the ink was dropwise casted onto a specular glassy carbon (GC) electrode ( $\sim 3 \mathrm{~mm}$ in diameter) with the final mass loading of $0.38 \mathrm{mg} \mathrm{cm}^{-2}$. OER performances were tested on an electrochemical workstation (Ivium-n-Stat, Ivium Technologies) with a standard three-electrode electrochemical cell. Saturated $\mathrm{Ag} / \mathrm{AgCl}$ was selected as the reference electrode and a platinum plate as the counter electrode. All linear sweep voltammetry (LSV) curves (and Tafel plots) were measured in $1 \mathrm{M}$ $\mathrm{NaOH}$ aqueous solution with a scan rate of $5 \mathrm{mV} \mathrm{s}^{-1}$. The potentials vs. $\mathrm{Ag} / \mathrm{AgCl}$ were converted to vs. RHE according to the Nernst Equation (1):

$E_{R H E}=E_{A g / A g C l}+E_{A g / A g C l}^{0}+0.059 * p H$

where $E_{\mathrm{RHE}}$ is the converted potential vs RHE, $E_{\mathrm{Ag} / \mathrm{AgCl}}^{0}=0.1976 \mathrm{~V}$, and $E_{\mathrm{Ag} / \mathrm{AgCl}}$ is the measured potential against the $\mathrm{Ag} / \mathrm{AgCl}$ reference. The applied potentials were $i R$ corrected manually, where $i$ refers to the current during the LSV tests and $R$ is the solution resistance obtained from the Nyquist plots, which were recorded from 
electrochemical impedance spectroscopy (EIS) tests at $1.6 \mathrm{~V}$ vs. RHE over frequencies of $1-10^{5} \mathrm{~Hz}$.

DFT Calculations. The projected density of states (PDOS) was calculated for P2$\mathrm{NaCoO}_{2}$ with three different structures $(100 \% \mathrm{Na}(2), 100 \% \mathrm{Na}(1)$, and $50 \% \mathrm{Na}(2)$ and $50 \% \mathrm{Na}(1)$ ), using density functional theory (DFT) with the Cambridge Serial Total Energy Package (CASTEP). A plane wave basis set with a cut-off energy of $500 \mathrm{eV}$ was chosen, and an exchange-correlation functional of the Perdew-Burke-Ernzerhof (PBE) type within the generalized gradient approximation (GGA) was selected. The lattice parameters used for the calculation are listed in Table S1 in the Supporting Information. For the geometry optimization, the convergence tolerances were set as follows: $5 \times 10^{-6} \mathrm{eV} /$ atom for the total energy, $0.01 \mathrm{eV} / \AA$ for the maximum force on atoms, $0.02 \mathrm{GPa}$ for the maximum stress, and $5 \times 10^{-4} \AA$ for the maximum atomic displacement. Brillouin-zone sampling for the calculations was conducted using the Monkhorst-Pack method with $12 \times 12 \times 2 k$ points. The calculations showed good convergence with respect to the cut-off energy and $k$ points. 


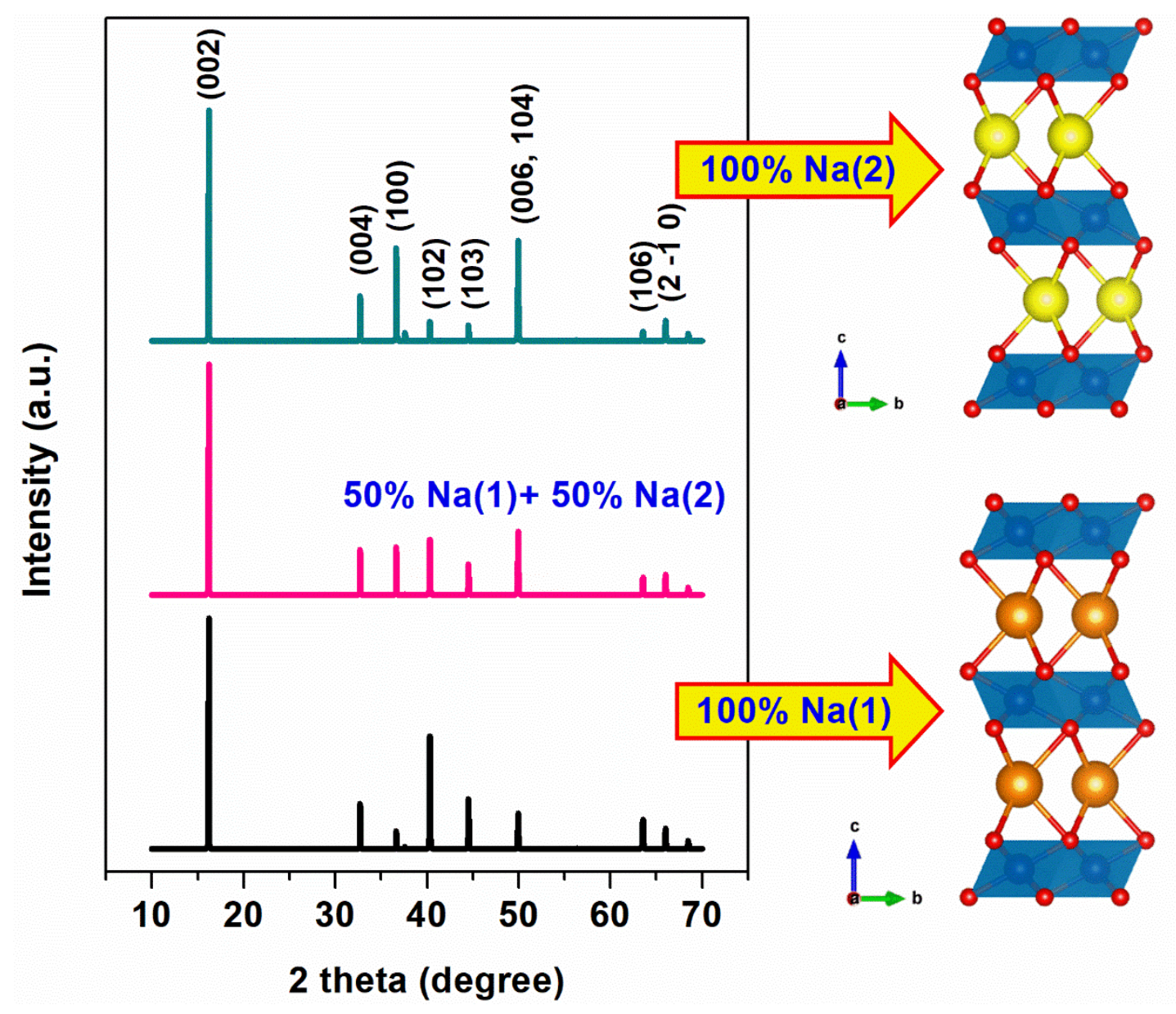

Figure S1. Calculated XRD patterns for three $\mathrm{P} 2-\mathrm{NaCoO}_{2}$ structures with different types of $\mathrm{Na}$ occupation. 

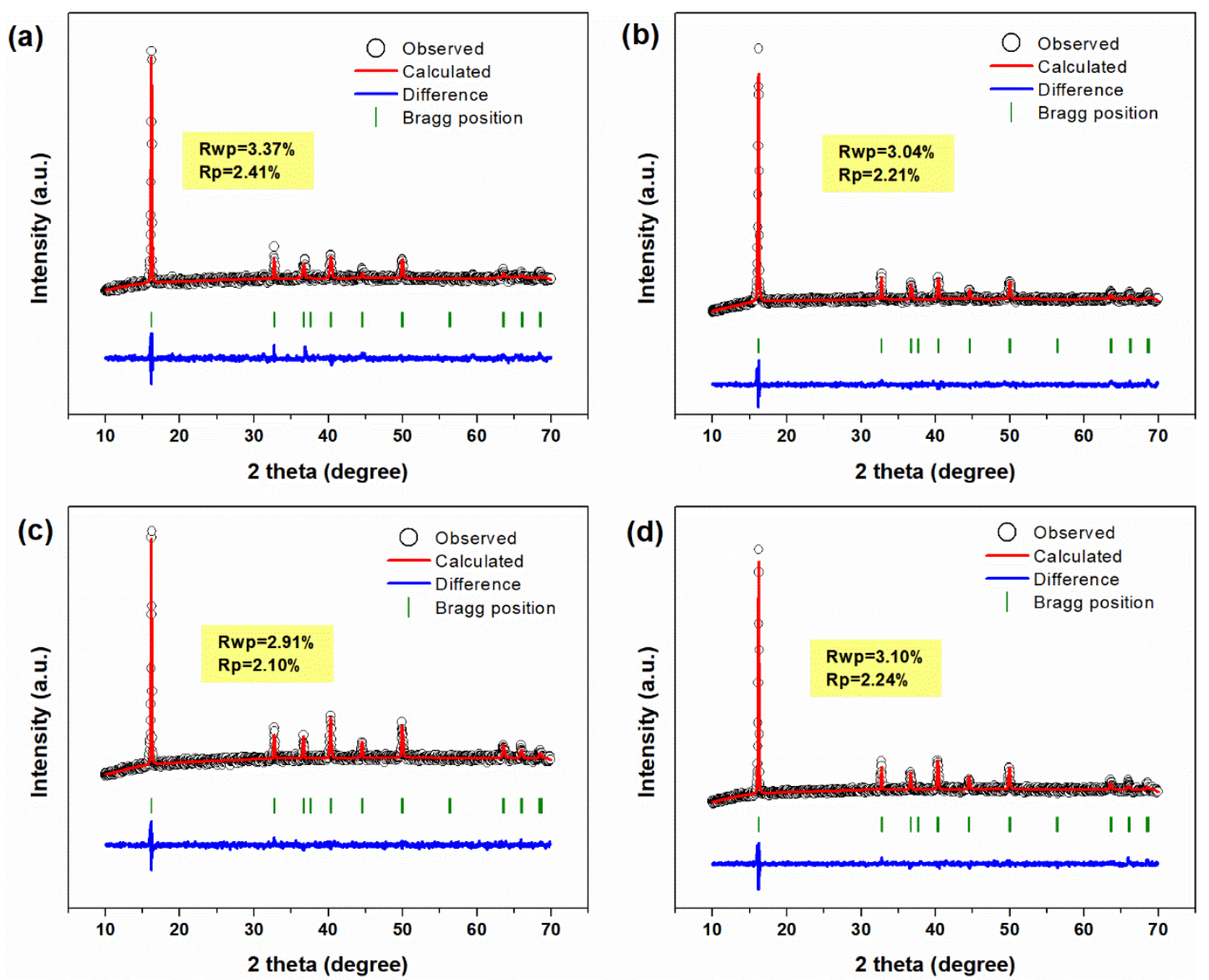

Figure S2. Refined XRD pattens for (a) NCO04 based on the $\mathrm{Na}(1)$ structure; (b) NCO05 based on both the $\mathrm{Na}(1)$ and the $\mathrm{Na}(2)$ structures; (c) NCO07 based on both the $\mathrm{Na}(1)$ and the $\mathrm{Na}(2)$ structures; (d) NCO08 based on the $\mathrm{Na}(2)$ structure. The detailed parameters see Table $\mathbf{S 3}$. 

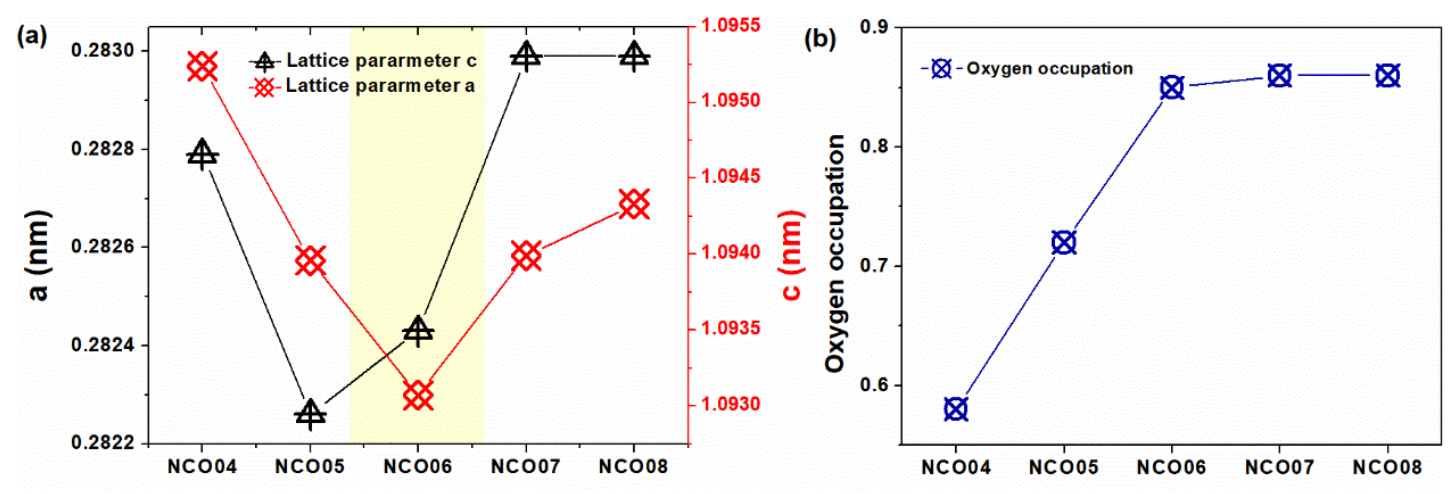

Figure S3. (a) The evolution of lattice parameters (a and c) versus the samples with different Na content; (b) The change in oxygen occupation for the samples from the refinements. 

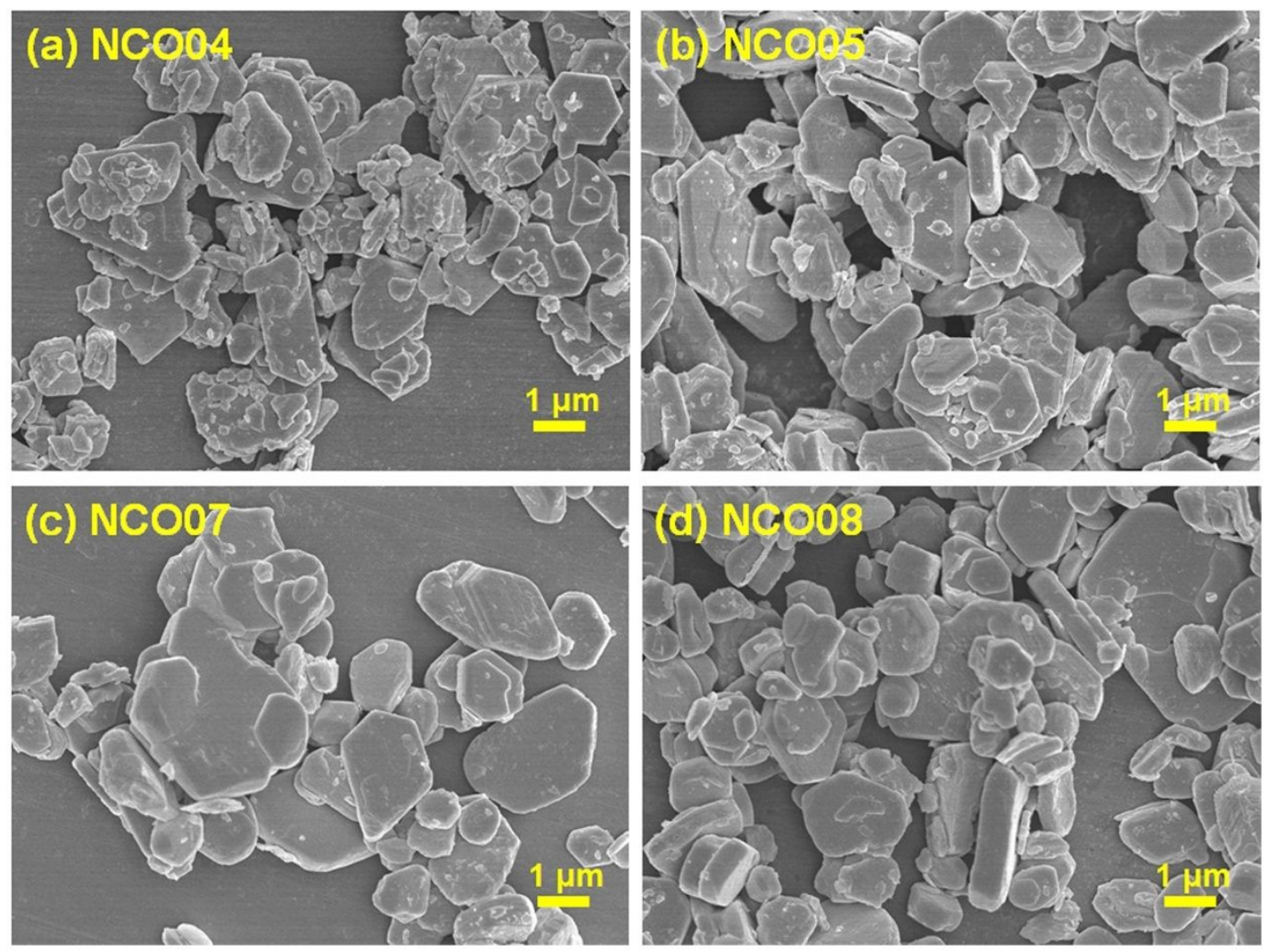

Figure S4. SEM images of (a) NCO04; (b) NCO05; (c) NCO07; (d) NCO08. 


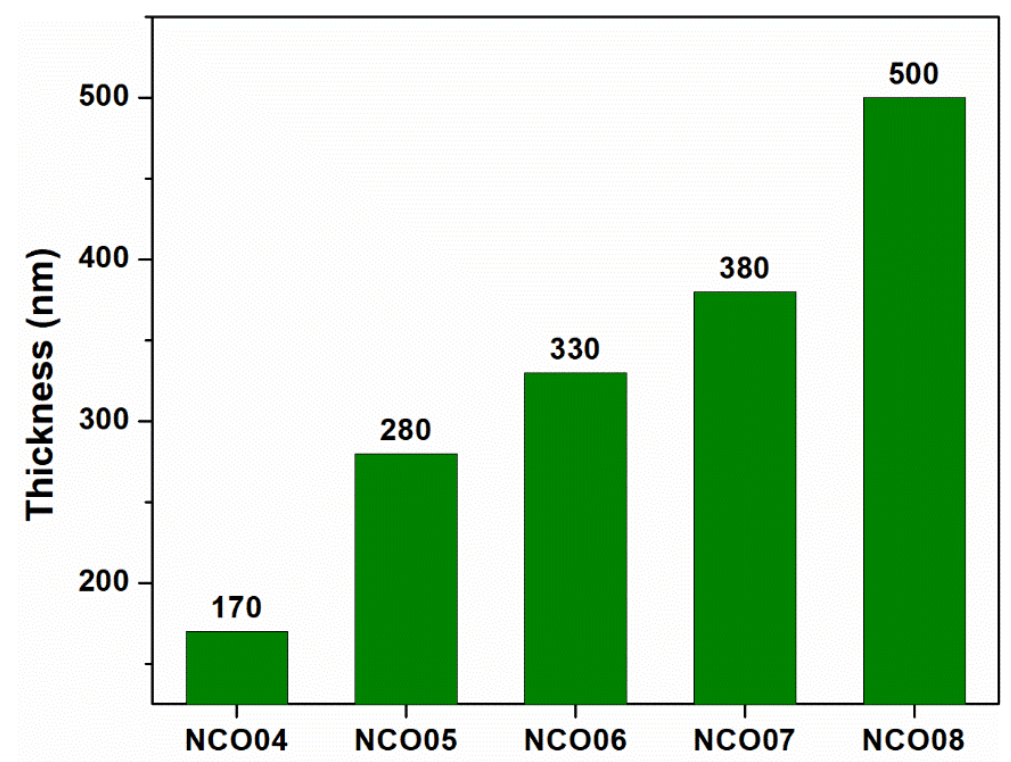

Figure S5. The average thickness of the plates from the different samples based on SEM images. 

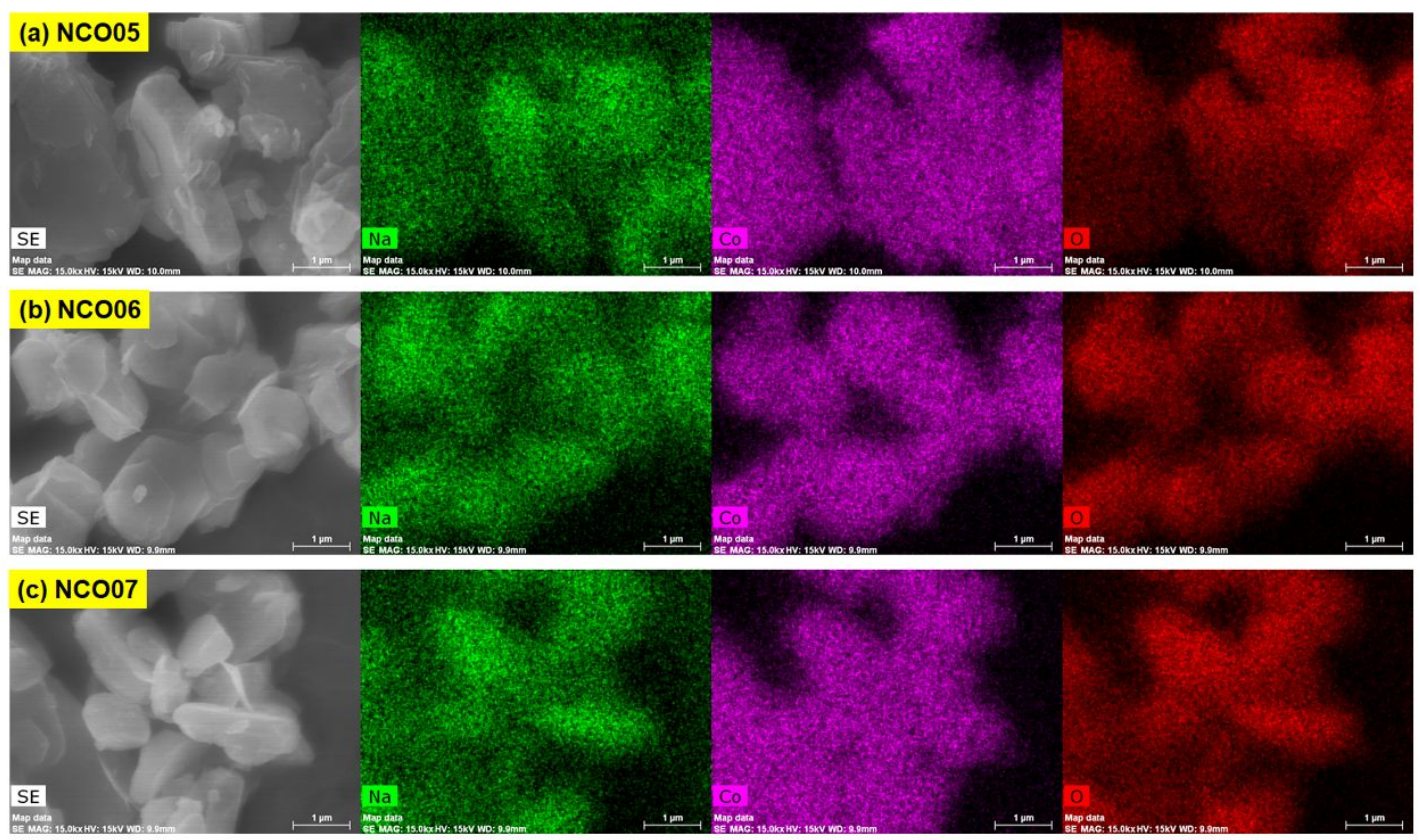

Figure S6. SEM element mappings for (a) NCO05; (b) NCO06; (c) NCO07. 


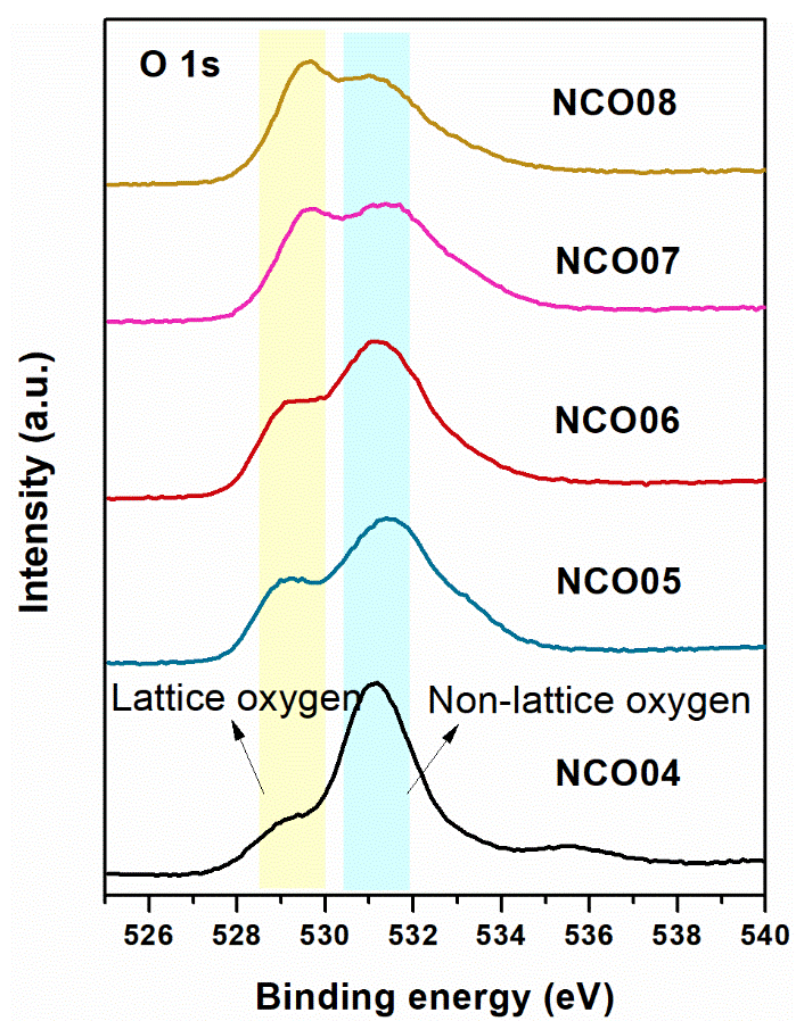

Figure S7. O 1s XPS of as-prepared samples. 

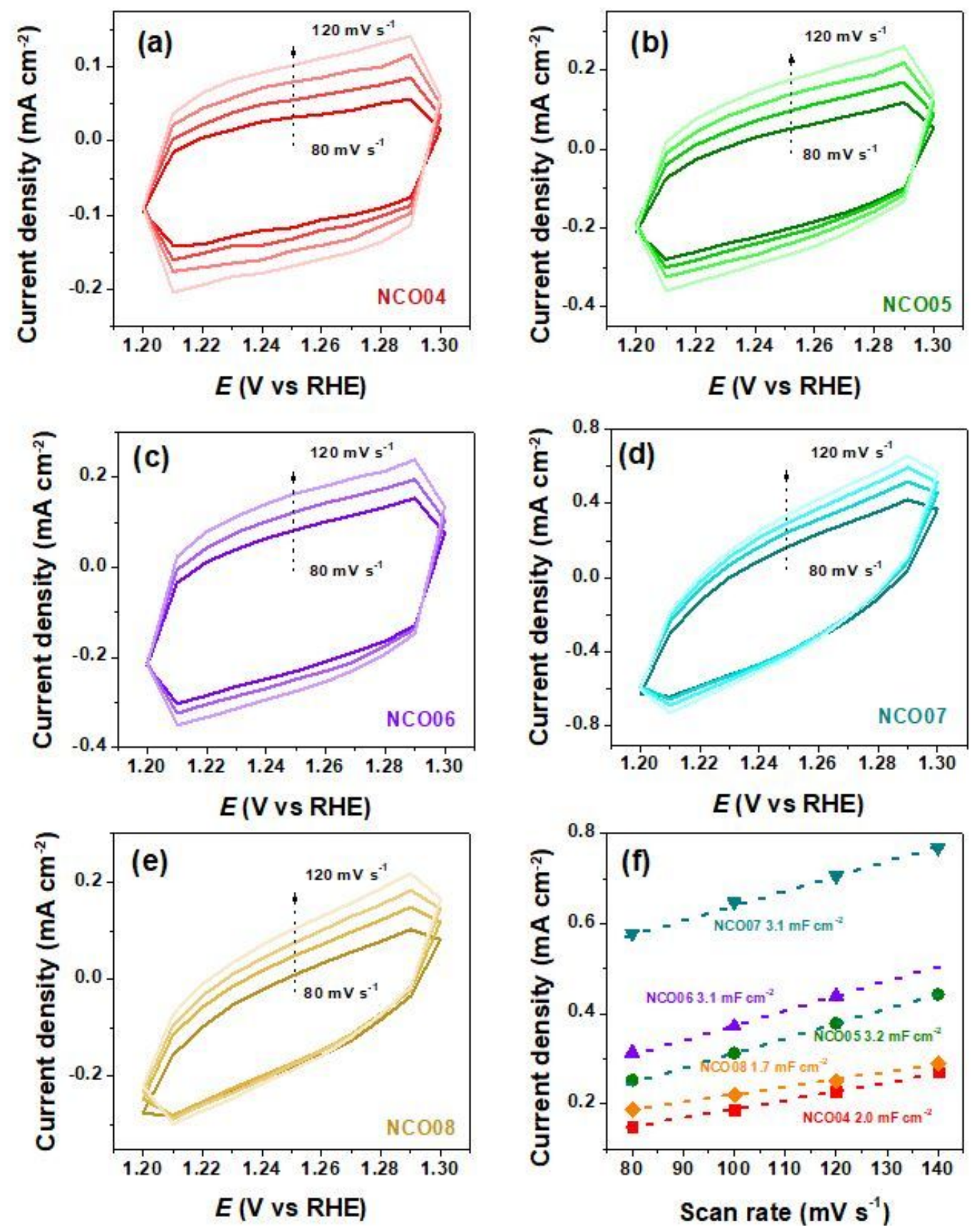

Figure S8. Cyclic voltammograms collected with different scan rates from 1.20-1.30 V vs RHE. (a) NCO04; (b) NCO05; (c) NCO06; (d) NCO07; (e) NCO08. (f) Current density difference at $1.25 \mathrm{~V}$ against different scan rates. 
Table S1. P2-NaCoO ${ }_{2}$; Space group: P 63/mmc; $\mathrm{a}=2.82842, \mathrm{~b}=2.82842, \mathrm{c}=$ $10.94800 \AA$.

\begin{tabular}{ccccc}
\hline $\mathrm{Na}(2)$ & $\mathrm{x}$ & $\mathrm{y}$ & $\mathrm{z}$ & Occ \\
\hline $\mathrm{Na} 2$ & 0.33333 & 0.66667 & 0.75000 & 1.000 \\
$\mathrm{Co}$ & 0.00000 & 0.00000 & 0.00000 & 1.000 \\
$\mathrm{O}$ & 0.33333 & 0.66667 & 0.08400 & 0.630 \\
\hline $\mathrm{Na}(2) \& \mathrm{Na}(1)$ & $\mathrm{x}$ & $\mathrm{y}$ & $\mathrm{z}$ & Occ \\
\hline $\mathrm{Na} 1$ & 0.00000 & 0.00000 & 0.25000 & 0.500 \\
$\mathrm{Na} 2$ & 0.33333 & 0.66667 & 0.75000 & 0.500 \\
$\mathrm{Co}$ & 0.00000 & 0.00000 & 0.00000 & 1.000 \\
$\mathrm{O}$ & 0.33333 & 0.66667 & 0.08400 & 0.630 \\
\hline $\mathrm{Na}(1)$ & 0.33333 & 0.66667 & 0.08400 & 0.630 \\
\hline $\mathrm{Na} 1$ & 0.00000 & 0.00000 & 0.25000 & 0.500 \\
$\mathrm{Co}$ & 0.00000 & 0.00000 & 0.00000 & 1.000 \\
\hline
\end{tabular}


Table S2. Refinement result parameters based on structures with different Na sites. Rp: profile R-factor.

\begin{tabular}{cccc}
\hline Sample & $\mathrm{Rp}(\mathrm{Na}(2))$ & $\mathrm{Rp}(\mathrm{Na}(2) \& \mathrm{Na}(1))$ & $\mathrm{Rp}(\mathrm{Na}(1))$ \\
\hline $\mathrm{NCO} 04$ & $2.49 \%$ & $2.43 \%$ & $\mathbf{2 . 4 1 \%}$ \\
$\mathrm{NCO} 05$ & $2.30 \%$ & $\mathbf{2 . 2 1 \%}$ & $\mathbf{2 . 2 5 \%}$ \\
$\mathrm{NCO} 06$ & $2.50 \%$ & $\mathbf{2 . 4 3 \%}$ & $2.47 \%$ \\
$\mathrm{NCO} 07$ & $\mathbf{2 . 1 7 \%}$ & $\mathbf{2 . 1 2 \%}$ & $2.20 \%$ \\
$\mathrm{NCO} 08$ & $\mathbf{2 . 2 4 \%}$ & $2.30 \%$ & $2.30 \%$ \\
\hline
\end{tabular}


Table S3. Refined lattice parameters from the structures with the smallest Rp values.

\begin{tabular}{|c|c|c|c|c|}
\hline \multirow{2}{*}{ NCO04 } & \multicolumn{2}{|c|}{$a=2.82790$} & \multicolumn{2}{|c|}{$\mathrm{c}=10.95240$} \\
\hline & $\mathrm{x}$ & $\mathrm{y}$ & $\mathrm{z}$ & Occ \\
\hline $\mathrm{Nal}$ & 0.00000 & 0.00000 & 0.25000 & 0.4000 \\
\hline $\mathrm{Co}$ & 0.00000 & 0.00000 & 0.00000 & 1.0000 \\
\hline $\mathrm{O}$ & 0.33333 & 0.66667 & 0.08400 & 0.5800 \\
\hline \multirow{2}{*}{$\mathrm{NCO} 05$} & \multicolumn{2}{|c|}{$\mathrm{a}=2.82260$} & \multicolumn{2}{|c|}{$c=10.93960$} \\
\hline & $\mathrm{x}$ & $\mathrm{y}$ & $\mathrm{z}$ & Occ \\
\hline $\mathrm{Na} 1$ & 0.00000 & 0.00000 & 0.25000 & 0.2500 \\
\hline $\mathrm{Na} 2$ & 0.33333 & 0.66667 & 0.75000 & 0.2500 \\
\hline $\mathrm{Co}$ & 0.00000 & 0.00000 & 0.00000 & 1.0000 \\
\hline $\mathrm{O}$ & 0.33333 & 0.66667 & 0.08400 & 0.7200 \\
\hline \multirow{2}{*}{ NCO06 } & \multicolumn{2}{|c|}{$\mathrm{a}=2.82430$} & \multicolumn{2}{|c|}{$\mathrm{c}=10.93070$} \\
\hline & $\mathrm{x}$ & $\mathrm{y}$ & $\mathrm{z}$ & Occ \\
\hline $\mathrm{Na} 1$ & 0.00000 & 0.00000 & 0.25000 & 0.3000 \\
\hline $\mathrm{Na} 2$ & 0.33333 & 0.66667 & 0.75000 & 0.3000 \\
\hline $\mathrm{Co}$ & 0.00000 & 0.00000 & 0.00000 & 1.0000 \\
\hline $\mathrm{O}$ & 0.33333 & 0.66667 & 0.08400 & 0.8500 \\
\hline \multirow{2}{*}{$\mathrm{NCO} 07$} & \multicolumn{2}{|c|}{$\mathrm{a}=2.82990$} & \multicolumn{2}{|c|}{$\mathrm{c}=10.93990$} \\
\hline & $\mathrm{x}$ & $\mathrm{y}$ & $\mathrm{z}$ & Occ \\
\hline $\mathrm{Na} 1$ & 0.00000 & 0.00000 & 0.25000 & 0.3500 \\
\hline
\end{tabular}




\begin{tabular}{ccccc}
$\mathrm{Na} 2$ & 0.33333 & 0.66667 & 0.75000 & 0.3500 \\
$\mathrm{Co}$ & 0.00000 & 0.00000 & 0.00000 & 1.0000 \\
$\mathrm{O}$ & 0.33333 & 0.66667 & 0.08400 & 0.8600 \\
\hline \multirow{2}{*}{$\mathrm{NCO} 08$} & $\mathrm{a}=2.82990$ & $\mathrm{c}=10.94330$ \\
\cline { 2 - 5 } & $\mathrm{x}$ & $\mathrm{y}$ & $\mathrm{z}$ & $\mathrm{Occ}$ \\
\hline \multirow{2}{*}{$\mathrm{Na} 2$} & 0.33333 & 0.66667 & 0.75000 & 0.8000 \\
$\mathrm{Co}$ & 0.00000 & 0.00000 & 0.00000 & 1.0000 \\
$\mathrm{O}$ & 0.33333 & 0.66667 & 0.08400 & 0.8600 \\
\hline
\end{tabular}


Table S4. State-of-the-art of $\mathrm{Na}_{\mathrm{x}} \mathrm{CoO}_{2}$ electrocatalyst performances in OER tests.

\begin{tabular}{|c|c|c|c|c|c|}
\hline Materials & Electrolyte & Electrode & $\eta(j=10$ & Tafel & Reference \\
& & & & & \\
\hline $\left.\mathrm{NaCoO}_{2}{ }^{-2}\right)$ & $1 \mathrm{M} \mathrm{KOH}$ & $\mathrm{GCE}$ & $430 \mathrm{mV}$ & 90 & 1 \\
\hline $\mathrm{Na}_{0.36} \mathrm{CoO}_{2}$ & $1 \mathrm{M} \mathrm{NaOH}$ & $\mathrm{RDE}$ & $415 \mathrm{mV}$ & - & 2 \\
\hline $\mathrm{Na}_{0.28} \mathrm{CoO}_{2}$ & $0.1 \mathrm{M} \mathrm{NaOH}$ & $\mathrm{RDE}$ & $350 \mathrm{mV}$ & 29 & 3 \\
\hline $\mathrm{Na}_{0.28} \mathrm{CoO}_{2}$ & $0.1 \mathrm{M} \mathrm{KOH}$ & RDE & $440 \mathrm{mV}$ & 55 & 4 \\
\hline $\mathrm{Na}_{0.67} \mathrm{CoO}_{2}$ & $0.1 \mathrm{M} \mathrm{KOH}$ & GCE & $290 \mathrm{mV}$ & 39 & 5 \\
\hline $\mathrm{Na}_{0.6} \mathrm{CoO}_{2}$ & $1 \mathrm{M} \mathrm{NaOH}$ & GCE & $392 \mathrm{mV}$ & 53 & This work \\
\hline
\end{tabular}

\section{REFERENCES}

(1) Li, Y.; Chen, G.; Zhu, Y.; Hu, Z.; Chan, T. S.; She, S.; Dai, J.; Zhou, W.; Shao, Z. Activating both basal plane and edge sites of layered cobalt oxides for boosted water oxidation. Adv. Funct. Mater. 2021, 2103569.

(2) Ji, H.; Sahasrabudhe, G.; Vallon, M. K.; Schwartz, J.; Bocarsly, A. B.; Cava, R. J. Investigating the origin of $\mathrm{Co}(\mathrm{IV})$ 's high electrocatalytic activity in the oxygen evolution reaction at a $\mathrm{Na}_{\mathrm{x}} \mathrm{CoO}_{2}$ interface. Mater. Res. Bull. 2017, 95, 285-291.

(3) Li, B.; Wang, T.; Li, X.; Zheng, X.; Wu, X.; Zhu, J.; Xu, H. Activating P2$\mathrm{Na}_{\mathrm{x}} \mathrm{CoO}_{2}$ for efficient water oxidation catalysis via controlled chemical oxidation. Mater. Today Chem. 2018, 10, 206-212. 
(4) Wang, G.; Yang, H.; Guan, J.; Huan, D.; Liu, Y.; Cai, H.; Peng, R.; Lu, Y. Accelerating oxygen evolution reaction via sodium extraction of $\mathrm{Na}_{0.71} \mathrm{CoO}_{2}$. Electrochim. Acta 2018, 268, 316-322.

(5) Wang, H.; Wu, J.; Dolocan, A.; Li, Y.; Lu, X.; Wu, N.; Park, K.; Xin, S.; Lei, M.; Yang, W.; et al. Short O-O separation in layered oxide $\mathrm{Na}_{0.67} \mathrm{CoO}_{2}$ enables an ultrafast oxygen evolution reaction. PNAS 2019, 116 (47), 23473-23479. 